\title{
Thoracic myeloradiculopathy due to multilevel ossification of ligamentum flavum
}

\author{
Yunus Kuntawi Aji \\ Abdul Hafid Bajamal \\ Rizki Meizikri \\ Muhammad Faris
}

Neurospine Division, Department of Neurosurgery Faculty of Medicine Universitas Airlangga/dr. Soetomo General Academic Hospital

Surabaya, Indonesia

\section{Cite this article:}

Aji YK, Bajamal AH, Meizikri R, Faris M. Thoracic myeloradiculopathy due to multilevel ossification of ligamentum flavum. Neurologico Spinale Medico Chirurgico. 2020.3(3): I 07-I I I. DOI: 10.36444/nsmc.v3i3.II8

Corresponding author:

Yunus Kuntawi Aji

Department of Neurosurgery Faculty of Medicine Universitas Airlangga/ dr. Soetomo General Academic Hospital, Diagnostic Center Building $5^{\text {th }}$ Floor, Surabaya, Indonesia

yunus.neurosurgery@gmail.com

\begin{abstract}
Ossification of ligamentum flavum (OLF) is calcification of the ligamentum flavum, which might narrow the spinal canal and causes myeloradiculopathy. This condition mainly affects the lower thoracal segment. Published reports on OLF are mostly from East Asia. There was only one Indonesian OLF case that had been published. The majority of OLF involves a single level only. This is the first Indonesian case-report on multilevel OLF. Through this case report, we aim to describe the natural history of the patient and our treatment strategy in managing the multilevel OLF case.
\end{abstract}

Delayed time to surgery is the key contributory factor in unfavorable surgical outcome in thoracic OLF. Choosing an appropriate surgical procedure is important. The neurological symptoms of the patient may not improve or worsen when an inadequate surgical procedure is used..

Keywords: Ligamentum flavum, ossification, calcification, thoracal, myelopathy, radiculopathy

\section{Introduction}

Ossification of ligamentum flavum (OLF) is a pathologic heterotrophic calcification of the ligamentum flavum which are more common at the lower thoracal segments. ${ }^{1,2}$ The presence of OLF might narrow the thoracic spinal canal and causes slowly-progressing myeloradiculopathy. ${ }^{3}$ The treatment of choice for OLF is surgical decompression, ${ }^{4}$ although microsurgical approaches and minimally invasive surgery have also been practiced. ${ }^{5,6}$

Published reports on OLF are mostly from East Asia, namely China, Japan, and South Korea, ${ }^{2,5,7,8}$ although cases from other ethnicities have been reported as well. ${ }^{8-10}$ One large study found that OLF is more prevalent among people aged 50-59 years old. ${ }^{11}$ A small Korean study found that the mean age of diagnosis was 60.9 years old, although the subjects ranged from 38 to 80 years old. ${ }^{3}$ There was only one Indonesian OLF case that had been published. ${ }^{12}$ To the best of our knowledge, this is the first published multilevel OLF case from Indonesia. Through this case report we aim to describe the natural history of the patient and our treatment strategy in managing multilevel OLF case. 


\section{Case report}

A 51-year-old female came to our hospital with chief complaint of numbness on the soles of her feet since 11 months before admission which had radiated to her waist and back since 3 months before admission. She also felt pain on activities or walking which improved upon resting. There was no sphincter dysfunction.

She initially went to physical medicine and rehabilitation clinic but never experienced significant improvement. Patient also had a history of traumatic event in which she fell from her motorcycle four months before admission. She was a housewife and frequently did the family's laundry with her back bending down.

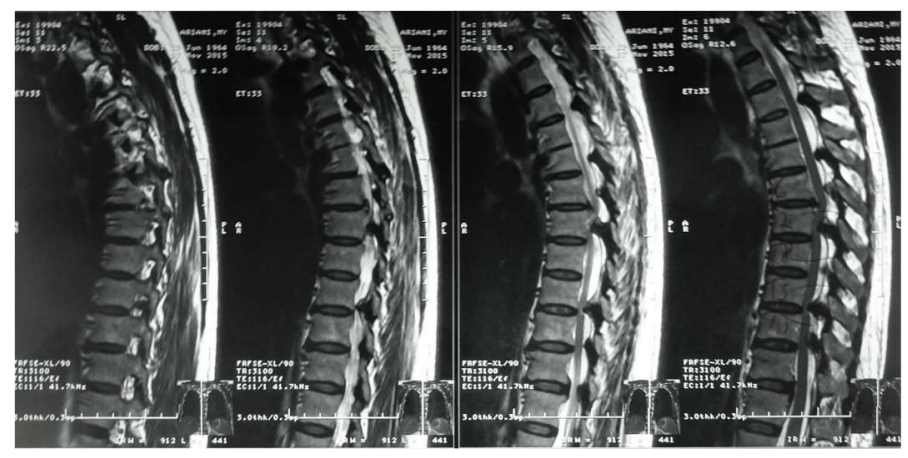

Figure 1. T2-weighted MRI of the patient. OLF at multiple level of thoracic vertebrae were identified (hypointense structures noted by the orange arrows). Evidence of canal stenosis and medullary compression was especially notable at T7-8 and T9-10 (blue arrow)

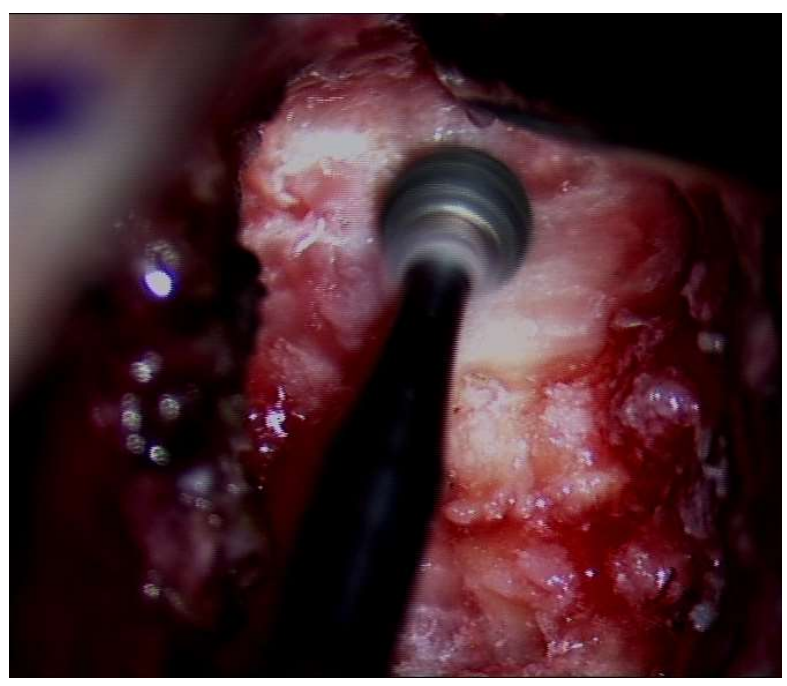

Figure 2. Intraoperative finding. The ossified ligamentum flavum was burred to decompress the canal.

Physical examination was significant for mild pain (visual analog score 3), intermittent claudication, hypoesthesia at the level of $11^{\text {th }}$ thoracic vertebrae (T11), and positive babinsky reflex on right lower extremity. All laboratory value was within normal limit. A T2weighted magnetic resonance imaging (MRI) revealed the presence of OLF at the level of T2-3, T4-5, T5-6, T7-8, T8-9, T9-10, and T10-11 (Fig. 1).

We diagnosed the patient with thoracal myeloradiculopathy and canal stenosis due to OLF at T2-3, T4-5, T5-6, T7-8, T8-9, T9-10, and T10-11. Preoperative modified Japanese Orthopedic Association (mJOA) score was 9 (Table 1) indicating that the patient had severe myelopathy. ${ }^{13}$ We performed decompressive laminotomy according to the level of the lesion and OLF removal (Fig. 2).

Postoperative motor function at first clinically worsened, but after oral medication with dexamethasone, it recovered gradually. There was no evidence of cerebrospinal fluid (CSF) leakage at the operative site. On postoperative day (POD) 7, the mJOA score improved one point on the sensory dysfunction aspect with Hirabayashi Recovery Rate (HRR) of 50\%, indicating fair recovery. ${ }^{14}$

Table 3. Assessment of mJOA score of the patient (in bold). Patient's lower extremity was severely affected. No autonomic dysfunction was noted.

\begin{tabular}{|c|c|}
\hline $\begin{array}{l}\text { Motor dysfunction score } \\
\text { of the upper extremity }\end{array}$ & $\begin{array}{l}\text { 0-Inability to move hands } \\
\text { 1-Inability to eat with a spoon, but able to move hands } \\
\text { 2-Inability to button shirt, but able to eat w/a spoon } \\
\text { 3-Able to button shirt w/great difficulty } \\
\text { 4-Able to button shirt w/slight difficulty } \\
\text { 5-No dysfunction }\end{array}$ \\
\hline $\begin{array}{l}\text { Motor dysfunction score } \\
\text { of the lower extremity }\end{array}$ & $\begin{array}{l}\text { 0-Complete loss of motor and sensory function } \\
\text { 1-Sensory preservation w/o ability to move legs } \\
\text { 2-Able to move legs, but unable to walk } \\
\text { 3-Able to walk on flat floor w/a walking aid (cane or crutch) } \\
\text { 4-Able to walk up and/or down stairs w/hand rail } \\
\text { 5-Moderate-to-significant lack of stability, but able to walk up } \\
\text { and/or down stairs w/o hand rail } \\
6 \text {-Mild lack of stability but walks w/smooth reciprocation unaided/ } \\
\text { 7-No dysfunction }\end{array}$ \\
\hline $\begin{array}{l}\text { Sensory } \\
\text { score of tysfunction } \\
\text { extremities }\end{array}$ & $\begin{array}{l}0 \text { - Complete loss of hand sensation } \\
\text { 1-Severe sensory loss or pain } \\
\text { 2-Mild sensory loss } \\
\text { 3-No sensory loss }\end{array}$ \\
\hline $\begin{array}{l}\text { Sphincter dysfunction } \\
\text { score }\end{array}$ & $\begin{array}{l}\text { 0-Inability to micturate voluntarily } \\
\text { 1-Marked difficulty with micturition } \\
\text { 2-Mild to moderate difficulty with micturition } \\
\text { 3-Normal micturition }\end{array}$ \\
\hline
\end{tabular}

\section{Discussion}

A simple, non-systematic search on Google Scholar yield 256 publications about OLF but only one was from Indonesia. The study reported a case of OLF at the level of T9-11. ${ }^{12}$ Our case-report is the first publication on multilevel OLF from Indonesia.

Our case-report, on the other hand, was about multilevel OLF in a 51-year-old female. Reports on prevalence of OLF based on age group has been diverse. A study on 993 cases of OLF found that this condition is more prevalent among people aged 50-59 years old and is more common among males. ${ }^{11}$ Kang and colleague found that the mean age at OLF diagnosis was 60.9 years old (range $38-80$ years old), but this publication was limited to only 51 patients who underwent 
decompressive laminotomy. ${ }^{3}$

Published OLF cases have mainly came from East Asia. ${ }^{2}$ A cross-sectional study from Korea on 2134 MRI images of patients with back pain revealed that thoracic OLF was found in $16.9 \%$ of the subjects. Contrary to the previously mentioned study, ${ }^{11}$ this study found that most patients were male. ${ }^{2}$ Guo and colleague did a similar study on 1736 Chinese subjects but found a relatively smaller number of case $(3.8 \%)$ with female predominance. The majority of findings was singlelevel OLF (68.2\%), while multiple level was found in $31.8 \%{ }^{15}$

Our patient came with chief complaint of numbness and intermittent claudication, indicating the presence of myelopathy. This numbness radiated to her waist and back. She was found hypoesthetic at T11, quite similar to described progression of the disease. ${ }^{16}$ The sensory symptoms of thoracal myeloradiculopathy due to OLF might vary from numbness to paresthesia, while motor ones range from slight weakness to severe spasticity. ${ }^{17}$ Autonom symptoms could present as sphincter dysfunction ${ }^{18,19}$ but these were not found in our case.

Diagnosis of OLF was based on whole spine MRI. The majority of OLF occurs at thoracal segments and rarely on cervical segments. ${ }^{7,20}$ The most common location is at lower thoracal ${ }^{2,11}$, and occasionally occur at upper thoracal. ${ }^{21}$ OLF presenting at multilevel is also possible. ${ }^{15,22}$ In fact, $10-25 \%$ of OLF involves multilevel. The decision to prefer whole spine MRI was due to the fact that as many as $15 \%$ of multilevel OLF were non-continuous. ${ }^{15}$ MRI focused on certain segments thus would risk missing some stenotic sites.

Consideration for surgical procedure preference was based on some factors: OLF with no ossification in the median portion of the lamina/lateral type/extended type/enlarged type, consider french-door laminectomy and fenestration; OLF with ossification in the midline of the lamina/ fused type/tuberous type, consider en bloc laminectomy; lateral/extended/enlarged types of unilateral OLF, consider hemilaminectomy; OLF with ossification of dura mater, consider en bloc laminectomy by removing the ossified mass and surrounding dura mater simultaneously while leaving the arachnoid intact. ${ }^{23}$

We did seven-level decompressive laminotomy according to the level of the lesion and OLF removal to relieve the canal stenosis. Decompressive laminotomy is the preferred treatment in such cases, ${ }^{24}$ although other techniques such as fenestration laminoplasty and hemilaminectomy have been utilized as well., 4,25,26 Although decompressive laminotomy is widely practiced in the case of OLF, functional status might remain poor after surgery. ${ }^{24}$ Dural tears have also been reported to complicate postoperative care. ${ }^{24} \mathrm{~A}$ retrospective study on multilevel OLF at thoracal and lumbal segments suggested that staged surgery can effectively achieve neurological recovery. However, there is always risk that the patient declines prior to second surgery. ${ }^{27}$ Case-reports on OLF recurrence after initial surgical decompression had also been reported. ${ }^{28}$

In our case, however, such complication did not occur and patient recovered gradually despite initially experienced worsening motor ability. Unfortunately, mJOA score improvement in our case was only one point on the sensory dysfunction aspect with fair recovery. A meta-analysis on post-laminectomy outcome found that the mean neurological improvement among OLF patients were 3.03 points on JOA score. ${ }^{24}$ Higher preoperative mJOA score was found to correlate with better recovery rate. ${ }^{29}$

To date, there is no agreed cut-off point on when to best operate on thoracic myelopathy due to OLF. Our patient had experienced this symptoms since 11 months prior to admission. In a study on 24 cases of OLF, duration of symptoms prior to surgical intervention was longer in those who recovered poorly, despite not statistically significant. ${ }^{29}$ Aizawa et al. reported in a retrospective study that shorter time-gap between onset of symptoms to surgical intervention yield better postoperative outcome among patients with thoracic myelopathy. ${ }^{30}$

Transient decrease in motor score was observed in out patient. Post-laminectomy neurological deterioration in thoracic myelopathy cases have been previously described. A retrospective study reported that this event was present in $13.7 \%$ of patients. Risk factors of postoperative deterioration was found to be spinal canal occupancy ratio > $70 \%$, intraoperative bleeding $>800 \mathrm{ml}$, and episode of mean arterial pressure $<81 \mathrm{mmHg} .{ }^{31}$ Preoperative signal change ratio on MRI also correlated with neurologic deterioration. ${ }^{8,32}$ Among cervical cases, acute postoperative weakness has been reported as well. A case report on patient with spondylotic cervical myelopathy found that acute weakness following cervical spine decompression improved after stabilizing patient's mean arterial pressure and corticosteroid administration. ${ }^{33}$

Acute neurological deterioration following decompressive spine surgery is thought to be due to ischemia-reperfusion injury. ${ }^{34} \mathrm{An}$ in vivo study on degenerative cervical myelopathy (DCM) mouse model, delayed decompression caused 1.5 to 2 fold increase of inflammatory cytokines. ${ }^{35}$ Early decompression, on the other hand, gave better neurological improvement and pain resolution. This finding indicated that after an ischemic insult to the spine, reperfusion of the spinal cord would induce inflammatory response which contribute to neurological worsening. ${ }^{36}$

Incident of neurological deterioration following decompression 
up to 24 hour after decompression had been known. ${ }^{36}$ It is said to be more common among elderly population and/or those with comorbidities such as atherosclerotic vessels and hypertension. ${ }^{37}$ Likewise, the patient in the present case-report presented to us 11 months after the onset of symptoms with history of hypertension.

\section{Conclusion}

Thoracic OLF is a common cause of thoracic myeloradiculopathy. Symptomatic thoracic OLF is usually progressive and refractory to conservative treatment. Eventhough there is no agreed cut-off point on when to best operate on thoracic myelopathy due to OLF, shorter time-gap between onset of symptoms to surgical intervention yield better postoperative outcome. Delayed time to surgery is the key contributory factor in unfavorable surgical outcome in thoracic OLF. Choosing an appropriate surgical procedure is important. The neurological symptoms of the patient may not improve or worsen when an inadequate surgical procedure is used.

\section{Acknowledgment}

None

\section{References}

1. Aizawa T, Sato T, Sasaki H, et al. Thoracic myelopathy caused by ossification of the ligamentum flavum: clinical features and surgical results in the Japanese population. SPI. 2006;5(6):514-519. DOI:10.3171/spi.2006.5.6.514

2. Moon BJ, Kuh SU, Kim S, et al. Prevalence, Distribution, and Significance of Incidental Thoracic Ossification of the Ligamentum Flavum in Korean Patients with Back or Leg Pain : MR-Based Cross Sectional Study. J Korean Neurosurg Soc. 2015;58(2):112. DOI:10.3340/jkns.2015.58.2.112

3. Kang KC, Lee CS, Shin SK, et al. Ossification of the ligamentum flavum of the thoracic spine in the Korean population: Clinical article. Journal of Neurosurgery: Spine. 2011;14(4):513-519. DOI:10.3171/2010.11.SPINE10405

4. Ahn DK, Lee S, Moon SH, et al. Ossification of the Ligamentum Flavum. Asian Spine Journal. 2014;8(1):89. DOI:10.4184/asj.2014.8.1.89

5. Ikuta K, Tarukado K, Senba H, et al. Decompression Procedure using a Microendoscopic Technique for Thoracic Myelopathy Caused by Ossification of the Ligamentum Flavum. Minim Invasive Neurosurg. 2011;54(05/06):271-273. DOI:10.1055/s-0031-1297986
6. Wang VY, Kanter AS, Mummaneni PV. Removal of ossified ligamentum flavum via a minimally invasive surgical approach: Case report. Neurosurgical Focus. 2008;25(2):E7. DOI:10.3171/FOC/2008/25/8/E7

7. Liang H, Liu G, Lu S, et al. Epidemiology of ossification of the spinal ligaments and associated factors in the Chinese population: a crosssectional study of 2000 consecutive individuals. BMC Musculoskelet Disord. 2019;20. DOI:10.1186/s12891-019-2569-1

8. Li Z, Ren D, Zhao Y, et al. Clinical characteristics and surgical outcome of thoracic myelopathy caused by ossification of the ligamentum flavum: a retrospective analysis of 85 cases. Spinal Cord. 2016;54(3):188-196. DOI:10.1038/sc.2015.139

9. Pascal-Mousselard H, Smadja D, Cabre P, et al. Ossification of the ligamenta flava with severe myelopathy in a black patient. A case report. Spine. 1998;23(14):1607-1608. DOI:10.1097/00007632199807150-00019

10. Pascal-Moussellard H, Cabre P, Smadja D, et al. Symptomatic ossification of the ligamentum flavum: a clinical series from the French Antilles. Spine (Phila Pa 1976). 2005;30(14):E400-5. DOI:10.1097/01.brs.0000169450.49181.91

11. Lang N, Yuan HS, Wang HL, et al. Epidemiological survey of ossification of the ligamentum flavum in thoracic spine: $\mathrm{CT}$ imaging observation of 993 cases. Eur Spine J. 2013;22(4):857-862. DOI:10.1007/s00586-012-2492-8

12. Yudoyono F, Dahlan RH, Ompusunggu SE, et al. Myelopathy caused by Ossification of Thoracic Ligamentum Flavum. Indonesian Journal of Rheumatology. 2016;8(1). DOI:10.37275/ijr.v8i1.11

13. Tetreault L, Kopjar B, Nouri A, et al. The modified Japanese Orthopaedic Association scale: establishing criteria for mild, moderate and severe impairment in patients with degenerative cervical myelopathy. Eur Spine J. 2017;26(1):78-84. DOI:10.1007/s00586-016-4660-8

14. Hirabayashi K, Miyakawa J, Satomi K, et al. Operative results and postoperative progression of ossification among patients with ossification of cervical posterior longitudinal ligament. Spine. 1981;6(4):354-364. DOI:10.1097/00007632-198107000-00005

15. Guo JJ, Luk KDK, Karppinen J, et al. Prevalence, distribution, and morphology of ossification of the ligamentum flavum: a population study of one thousand seven hundred thirty-six magnetic resonance imaging scans. Spine. 2010;35(1):51-56. DOI:10.1097/BRS.0b013e3181b3f779

16. Feng F, Sun C, Chen Z. Progress on Clinical Characteristics and Identification of Location of Thoracic Ossification of the Ligamentum Flavum. Orthop Surg. 2015;7(2):87-96. DOI:10.1111/os.12165

17. Yamada T, Torigoe I, Sakai K, et al. Contiguous Multilevel Thoracic Ossification of Ligamentum Flavum in a Young Adult Spine. Case Reports in Orthopedics. DOI: 10.1155/2019/1640485 
18. Toledo JA, Isseldyk FV, Re M, et al. Ossification of the ligamentum flavum as cause of thoracic cord compression: Case report of a Latin American man and review of the literature. Surg Neurol Int. 2013;4. DOI:10.4103/2152-7806.118489

19. Lee BJ, Park JH, Jeon SR, et al. Clinically significant radiographic parameter for thoracic myelopathy caused by ossification of the ligamentum flavum. Eur Spine J. 2019;28(8):1846-1854. DOI:10.1007/s00586-018-5750-6

20. Miyazawa N, Akiyama I. Ossification of the ligamentum flavum of the cervical spine. J Neurosurg Sci. 2007;51(3):139-144.

21. Wang $\mathrm{H}$, Wei $\mathrm{F}$, Long $\mathrm{H}$, et al. Surgical outcome of thoracic myelopathy caused by ossification of ligamentum flavum. Journal of Clinical Neuroscience. 2017;45:83-88. DOI:10.1016/j.jocn.2017.07.008

22. Mori K, Kasahara T, Mimura T, et al. Prevalence, distribution, and morphology of thoracic ossification of the yellow ligament in Japanese: results of CT-based cross-sectional study. Spine. 2013;38(19):E1216-1222. DOI:10.1097/BRS.0b013e31829e018b

23. Tanaka Y, Sato T, Aizawa T. Surgery for ossification of the ligamentum flavum. In: Yonenobu K, Nakamura K, Toyama Y, editors. OPLL. 2nd Ed. Japan: Springer; 2006:265-269.

24. Osman NS, Cheung ZB, Hussain AK, et al. Outcomes and Complications Following Laminectomy Alone for Thoracic Myelopathy due to Ossified Ligamentum Flavum. Spine (Phila Pa 1976). 2018;43(14):E842-E848. DOI:10.1097/BRS.0000000000002563

25. Okada K, Oka S, Tohge K, et al. Thoracic myelopathy caused by ossification of the ligamentum flavum. Clinicopathologic study and surgical treatment. Spine. 1991;16(3):280-287. DOI:10.1097/00007632-199103000-00005

26. Onishi E, Yasuda T, Yamamoto H, et al. Outcomes of Surgical Treatment for Thoracic Myelopathy: A Single-institutional Study of 73 Patients. Spine. 2016;41(22):E1356-E1363. DOI:10.1097/BRS.0000000000001622

27. Li W, Guo S, Sun Z, et al. Multilevel thoracic ossification of ligamentum flavum coexisted with/without lumbar spinal stenosis: staged surgical strategy and clinical outcomes. BMC Musculoskelet Disord. 2015;16(1):206. DOI:10.1186/s12891-015-0672-5

28. Kanno H, Takahashi T, Aizawa T, et al. Recurrence of ossification of ligamentum flavum at the same intervertebral level in the thoracic spine: a report of two cases and review of the literature. Eur Spine J. 2018;27(Suppl 3):359-367. DOI:10.1007/s00586-017-5281-6

29. Kim JK, Ryu HS, Moon BJ, et al. Clinical Outcomes and Prognostic Factors in Patients With Myelopathy Caused by Thoracic Ossification of the Ligamentum Flavum. Neurospine. 2018;15(3):269-276. DOI:10.14245/ns.1836128.064

30. Aizawa T, Sato T, Sasaki H, et al. Results of surgical treatment for thoracic myelopathy: minimum 2-year follow-up study in 132 patients. SPI. 2007;7(1):13-20. DOI:10.3171/SPI-07/07/013

31. Wang H, Ma L, Xue R, et al. The incidence and risk factors of postoperative neurological deterioration after posterior decompression with or without instrumented fusion for thoracic myelopathy. Medicine (Baltimore). 2016;95(49). DOI:10.1097/MD.0000000000005519

32. Zhang J, Wang L, Li J, et al. Predictors of surgical outcome in thoracic ossification of the ligamentum flavum: focusing on the quantitative signal intensity. Sci Rep. 2016;6:23019. DOI:10.1038/srep23019

33. Iv JW, Brazdzionis J, Mohrdar C, et al. Spinal Cord Reperfusion Injury: Case Report, Review of the Literature, and Future Treatment Strategies. Cureus Journal of Medical Science. 2019;11(7). DOI:10.7759/cureus.5279

34. Wiginton JG, Brazdzionis J, Mohrdar C, et al. Spinal Cord Reperfusion Injury: Case Report, Review of the Literature, and $\begin{array}{llll}\text { Future } & \text { Treatment } & \text { Strategies. }\end{array}$ DOI: $10.7759 /$ cureus.5279

35. Vidal PM, Karadimas SK, Ulndreaj A, et al. Delayed decompression exacerbates ischemia-reperfusion injury in cervical compressive myelopathy. JCI Insight. 2(11). DOI:10.1172/jci.insight.92512

36. Karadimas SK, Laliberte AM, Tetreault L, et al. Riluzole blocks perioperative ischemia-reperfusion injury and enhances postdecompression outcomes in cervical spondylotic myelopathy. Science Translational Medicine. 2015;7(316):316ra194-316ra194. DOI:10.1126/scitranslmed.aac6524

37. Tetreault, Lindsay, Kopjar B, et al. A Clinical Prediction Rule for Functional Outcomes in Patients Undergoing Surgery for Degenerative Cervical Myelopathy: Analysis of an International Prospective Multicenter Data Set of 757 Subjects. The Journal of Bone and Joint Surgery. 2015;97(24):2038-2046. DOI: 10.1055/s0036-1582782

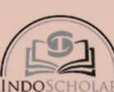
Articles published online under this model are officially published and can be cited and quoted using the DOI as the reference source. Neurologico Spinale Medico Chirurgico has a policy that changes will not be made after publication of an article without following accepted procedures for making corrections to the scientific record. The entire contents of the Neurologico Spinale Medico Chirurgico are licensed under the Creative Commons Attribution 4.0 International License. You are free to share - copy \& redistribute the material in any medium or format, adapt - remix, transform, and build upon the material for any purpose, even commercially. Under the following terms, you must give appropriate credit, provide link to the license, and indicate if changes were made. You may do so in any reasonable manner, but not in any way that suggests the licensor endorses you or your use. 